\title{
Aanpassing en toetsing van die Rothwell-Miller-belangstellingsvraelys
}

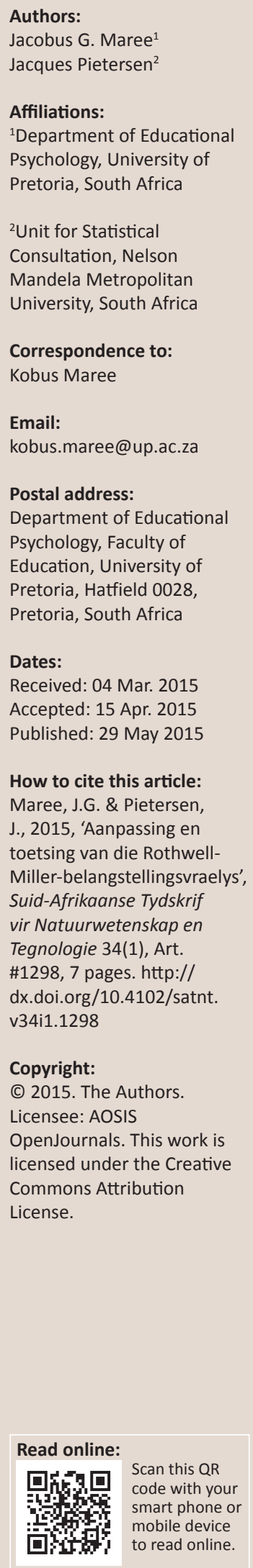

Die doel van hierdie studie was om 'n bestaande, maar uiters verouderde belangstellingsvraelys (Rothwell-Miller-belangstellingsvraelys [RMBV]) aan te pas. In die eerste fase is vier provinsies by wyse van doelsteekproeftrekking geselekteer: een stedelik en drie plattelands of semiplattelands. In fase twee is 'n steekproef van 518 Graad 11-leerders met behulp van doelsteekproeftrekking geselekteer (gemiddelde ouderdom $[x]$ manlik $=17.52$ jaar, vroulik $=$ 17.39 jaar; standaardafwyking $[s]$ manlik $=0.97$ jaar, vroulik $=0.93$ ) in agt skole, verdeel volgens onderrigtaal (Afrikaans/Engels) en streek (stedelik/plattelands/semiplattelands). Statistiese analises het die vasstelling van betroubaarheid ingesluit by wyse van die berekening van Cronbach se $\alpha$, asook die halfverdelingsmetode. Die data is verder geanaliseer by wyse van statistiese tegnieke soos $t$-toetse, ANOVA, asook Tukey se Honest Significant Differencetoets (HSD). Die resultate word bespreek en die gevolgtrekking word gemaak dat hoewel die aangepaste vraelys tot 'n nuttige instrument vir gebruik in Suid-Afrika ontwikkel kan word, verdere navorsing eers nodig is.

Adaptation and implementation of the Rothwell-Miller Interest Blank. The aim of this study was to adapt an existing but extremely dated interest questionnaire, the RothwellMiller Interest Blank (RMIB). In the first phase, four provinces were selected purposively: one urban and three rural or semirural. Secondly, a purposeful sample of 518 Grade 11 learners in eight schools was selected (mean age $[x]$ Male $=17.52$ years, Female $=17.39$ years; standard deviation[s] Male $=0.97$ years, female $=0.93$ ), divided according to medium of instruction (Afrikaans/English) and area (urban/rural/semirural area). Statistical analyses included determining of reliability by calculating Cronbach's $\alpha$ and the split-half reliability. The data was further analysed by means of statistical techniques including $t$-test, ANOVA and Tukey's HSD. Results are discussed and the study concludes that although the adapted questionnaire could be a valuable instrument for use in South Africa, further research is required.

\section{Inleiding}

\section{Beroepsvoorligting in 'n vinnig veranderende wêreld}

Die wêreld van werk verander deurgaans. Tewens, dit verander tans vinniger as ooit tevore in die geskiedenis, en werksomgewings word gevolglik toenemend minder stabiel. Die invloede wat die hedendaagse ekonomiese realiteite en die veranderende werkswêreld op die praktyk van beroepsvoorligting uitoefen, is oral te bespeur. Werkers word al minder permanent aangestel, bevind hulle al hoe korter in beroepe terwyl onsekerheid oor hul toekoms in bepaalde organisasies toeneem. Korttermynopdragte is aan die orde van die dag (Aswathappa 2005). Terwyl sommige beroepsrigtings verdwyn, verskyn ander voortdurend. Hierdie veranderinge stel noodwendig hoë en toenemend hoër eise aan werkers, maar veral aan leerders (insluitend skoliere, studente, voornemende werkers en werksoekers) en derhalwe ook aan beroepsvoorligters. In 'n poging om 'n greep te kry op die fundamentele veranderinge in die wêreld van werk, poog teoretici, maar ook praktisyns voortdurend om nuwe terme te skep aan die hand waarvan die veranderinge beskryf kan word ten einde orde te skep in 'n werkswêreld wat al onsekerder word. Dit sluit terme in soos die volgende (Maree 2013a; 2013b; Savickas 2013):

- Aangepaste ('customised') beroepe: Talle beroepsbeoefenaars pas hul werksportefeuljes sodanig aan dat hul werkstaak in die eerste plek met hul persoonlike behoeftes in plaas van die behoeftes van werkgewers belyn word (Benko \& Weisberg 2007).

- Kaleidoskopiese ('kaleidoscopic') beroepe: Beroepe word al meer in ooreenstemming met werkers se eie terme geskep; gedefinieer deur hul eie waardes, keuses en voorkeure (Mainiero \& Sullivan 2005).

- Postindustriële ('postindustrial') beroepe: Hierdie term dui daarop dat die idee van 'n 'stabiele' werksomgewings aan 't verdwyn is. Werkgewers moet hulself dus herhaaldelik in werksomgewings herdefinieer (Gershuny 1993). 
- Die grenslose ('boundaryless') beroep: Hierdie term dui op 'n strewe na onafhanklikheid by werkers; weg van tradisionele ooreenkomste met organisasies (Arthur 1994; Arthur \& Rousseau 1996).

- Die portefeulje- ('portfolio') beroep: Werknemers kontrakteer, 'verkoop' of 'verhuur' toenemend hul dienste in verskillende kontekste en beding selfindiensnemingskontrakte (Handy 1995).

Die Proteus- ('Protean') beroep: Hierdie term impliseer dat werkers toenemend veerkrag aan die dag lê en aanpas (hulself hernu) ten einde in staat te wees om die effek van nuwe tegnologiese ontwikkelings en nuwe ontwikkelings in die werkswêreld te hanteer (Hall 1996; Baruch 2004).

Die effek van ingrypende veranderinge in die wêreld van werk (op verskillende vlakke, soos hierbo omskryf) word in Suid-Afrika ewe sterk as elders ervaar (Kraak 2010). Savickas (2011a) skryf die verwardheid en onsekerheid wat tans by soveel werkers bespeur word toe aan die talle ingrypende veranderinge wat oor die afgelope aantal dekades plaasgevind het en steeds plaasvind (hoofsaaklik vanweë die effek van die vierde en vyfde ekonomiese golf [Gurri 2013]). Hy benadruk dit dat die behoefte aan beroepsvoorligting, insluitend die bepaling van leerders se belangstellings, al groter word en steeds groter sal word. Toetsing met die oog op beroepsvoorligting kan immers substansieel daartoe bydra om beroepsvoorligters in staat te stel om leerders te help om 'n studierigting of loopbaan te kies, maar ook om hulself te konstrueer en 'n suksesvolle lewe te ontwerp.

\section{Wie help leerders om hul belangstellings te bepaal?}

Hoewel ouers, familielede, onderwysers, vriende en dies meer sonder twyfel die beste belange van leerders (maar ook van ander persone op soek na beroepsvoorligting) op die hart dra, kan dit kwalik van hulle verwag word om 'n kennersmening te gee rakende welke beroepe of studierigtings leerders kan of behoort te oorweeg. Hul kennis van sake soos die wêreld van werk, verskillende studie- en beroepsrigtings, asook van verskillende opleidingsgeleenthede en -instansies is tog beperk. Die rol van beroepsvoorligters is in verreweg die meeste gevalle onontbeerlik ten einde leerders te help om toepaslike beroepskeuses te maak (waarby aspekte soos vakvoorligting en die keuse van 'n bepaalde studie-instansie ingesluit is).

\section{Tegnieke om beroepsvoorligting te verskaf}

Daar word van etlike metodes gebruik gemaak om persone se belangstellings te bepaal. Dit sluit die volgende in:

- observasie (persone wat bepaalde beroepsverwante aktiwiteite uitvoer, word in hul natuurlike omgewings waargeneem)

- onderhoudvoering (persone word oor hul belangstellings uitgevra)

- toetsing (die afneem van sielkundige toetse om belangstellings te bepaal)

- die inskakeling van informele belangstellingsvraelyste.

\section{Die gebruik van belangstellingstoetse in die beroepsvoorligtingsproses}

Die rol van belangstelling in die keuse van 'n beroep word algemeen aanvaar. Cochran (1997:151) stel die saak soos volg: 'Clearly, interest profiles constitute ... one ... very important aspect of that intricate configuration of factors which, collectively, account for the variance in people's eventual career choices.'

Aangesien belangstelling dus 'n kritiese aspek uitmaak van toetsing met die oog op beroepsvoorligting, spreek dit boonop vanself dat beroepsvoorligters tydens sodanige toetsing soveel moontlik behoort te doen om persone se prominentste belangstellings vas te stel alvorens beroepsvoorligting kan geskied. Dit is immers al oor en oor bewys dat belangstelling (soos gemeet deur gestandaardiseerde vraelyste of toetse) 'n nuttige rol speel by die vasstelling van persone se mees gepaste studierigting of beroepskeuse (Ainley, Jones \& Navaratnam 1990; Gati, Fishman-Nadav \& Shiloh 2006; Patrick, Care \& Ainley 2011).

\section{Heersende teoretiese benadering tot beroepsvoorligting}

Die benadering tot en praktyk van beroepsvoorligting in die 21ste eeu het vanweë fundamentele veranderinge in die wêreld van werk ingrypend verander (Maree 2012). Dit is grootliks die resultaat van die uitwerking van die vierde en vyfde ekonomiese golf en verwante veranderinge op die globale ekonomie. Savickas (1993) het voorgestel dat die aksent in beroepsvoorligting van beroepsontwikkeling na selfontwikkeling moet verskuif en sy voorstel opgevolg met die ontwikkeling van 'n benadering tot beroepsvoorligting wat algemeen as beroepskonstruksie bekend staan (Savickas 2005; 2011a, 2011b). In wese kom hierdie benadering daarop neer dat beroepsvoorligting wêreldwyd hervorm is vanaf ' $n$ hoofsaaklik kwantitatiewe, positivistiese of eienskap- en faktorbenadering (['trait and factor'], Hartung 2013; Holland 1997; Parsons 1909) na 'n geïntegreerde, kwalitatiewe+kwantitatiewe benadering (Savickas 2000, 2007). Hierdie benadering beklemtoon die bemagtiging van kliënte om self keuses te maak (insluitend die maak van 'n beroepskeuse), in plaas daarvan om tydens beroepsvoorligting feitlik eksklusief te fokus op persoonseienskappe ('traits') (soos persoonlikheid [insluitend belangstelling], waardes, studieoriëntasie, intelligensie en aanleg), asook beroepsvereistes en dan 'n sogenaamde optimale passing tussen hierdie twee aspekte te probeer vind.

Ons praktykbenadering is om die sogenaamde toetsbenadering in samehang met die narratiewe benadering in te skakel. Met ander woorde, ons huldig die standpunt dat dit steeds essensieel is om 'positivistiese' toetse (insluitend belangstellingsvraelyste) te ontwerp, in samehang met vraelyste van 'n meer narratiewe aard. Volgens Savickas (2011a) reflekteer belangstellingsvraelyste immers baie aanvanklik nuttige aspekte wat beroepskeuses onderlê. Die 'objektiewe' inligting wat met behulp van hierdie tipe vraelyste bekom word, kan dan toepaslik aangevul word deur inligting wat met behulp van 'n kwalitatiewe (narratiewe of 
storie-) benadering bekom word ten einde beroepsvoorligters en hul kliënte te help om ook 'subjektiewe' aspekte van hul beroeps- en lewensverhaal in diepte te verken.

In die volgende afdeling word spesifiek gefokus op die teoretiese basis van die RMBV (die Rothwell-Millerbelangstellingsvraelys [ontwikkel deur Hall, Halstead \& Taylor 1986]), 'n uitsluitlik positivistiese vraelys wat in die onderhawige studie aangepas en uitgetoets is.

\section{Teoretiese basis van die Rothwell-Miller- belangstellingsvraelys}

\section{Persoon-omgewingteorie [Trait and factor theory]}

Hierdie teorie word algemeen beskou as 'n klassieke, teoretiese perspektief op beroepsverwante gedrag (Hartung 2013; Holland 1997; Parsons 1909). Hiervolgens is die fokus in beroepsvoorligting feitlikuitsluitlikop diesoekena'noptimale 'passing' tussen iemand se persoonlikheidseienskappe (['traits'] soos persoonlikheid, insluitend belangstelling, waardes, studieoriëntasie, intelligensie en aanleg) aan die een kant, en beroepsvereistes aan die ander kant ten einde die sogenaamde 'beste' beroep vir hom of haar te vind. Parsons (1909) en Holland $(1985,1997)$ se teoretiese benaderings impliseer dat temas ten aansien van persone se beroepsbelangstellings by moontlike werksomgewings behoort te pas. Die RMBV is op hierdie teorie gebaseer.

\section{Stereotipiese beroepskategorieë}

Kuder (Kuder 1975, 1977; Low et al. 2005) het ook geglo dat beroepsvoorligters hul kliënte moet help soek na 'n sogenaamde 'optimale passing' tussen persoonlikheidsprofiel en werksomgewing. Volgens Kuder kan 10 onderskeibare stereotipiese beroepskategorieë geïdentifiseer word, naamlik wetenskaplik, artisties, literêr, maatskaplike dienste, musikaal, buitelug, rekenkundig, administratief, oorredend, asook meganies. Hierdie 10 kategorieë sluit nou aan by Holland $(1985,1997)$ se alombekende sesvoudige beroepstipologie (Realisties, Wetenskaplik, Artisties, Sosiaal, Ondernemend, asook Administratief). Wetenskaplik, Sosiaal en Ondernemend (herbenoem as Oorredend) is behou, terwyl Realisties verfyn is tot Buitelug en Meganies, Artisties tot Literêr, Artisties, Maatskaplike Diens en Musikaal, en Konvensioneel tot Administratiewe en Rekenkundige voorkeure. Rothwell en Miller (Miller 1968; Hall et al. 1986; Miller, Tyler \& Rothwell 1994), ontwikkelaars van die RMBV, daarenteen, het ook hul werk op Holland se tipologie gebaseer, maar gewerk vanuit die perspektief dat 12 onderskeibare, stereotipiese beroepskategorieë geïdentifiseer kon word, naamlik Buitelug, Meganies, Rekenkundig, Wetenskaplik, Oorredend, Artisties, Literêr, Musikaal, Maatskaplike diens, Administratief, Prakties, asook Medies. Die RMBV-ontwikkelaars het egter hul werk gebaseer op die volgende drie aannames, wat wyd gehuldig word, (Du Toit 1992; Gevers, Du Toit \& Harilall 1995; Kuder 1977):

- Beroepe en beroepsrigtings kan geklassifiseer word in terme van 'n arbitrêre aantal stereotipiese, algemeen aanvaarde werksomgewings.
- Hierdie stereotipiese werksomgewings korreleer sterk positief met persone se beroepsbelangstellings en -voorkeure. Met ander woorde, werksomgewings stem sterk ooreen met persoonlikheidstipes.

- Persone se antwoorde op vrae oor stereotipiese, algemeen aanvaarde werksomgewings (of beroepskategorieë) lewer insiggewende en belangrike inligting rakende hul belangstellings in of voorkeur ten opsigte van hierdie stereotipes.

\section{Doel van die studie}

Die doel van hierdie studie is om ondersoek in te stel na die moontlikheid om die Rothwell-Miller- belangstellingsvraelys ([RMBV] deur Miller, Tyler \& Rothwell 1994), wat sowat 60 jaar gelede ontwikkel is en intussen erg verouder het, te probeer opdateer en aanpas vir gebruik in die 21ste eeu (in 'n Suider-Afrikaanse konteks).

\section{Metode}

\section{Paradigmatiese perspektief}

Die studie is vanuit die geïntegreerde, kwantitatiewe+ kwalitatiewe epistemologie onderneem. Met ander woorde, die kwantitatiewe aspek van die studie, waartydens daar op statistiese berekenings en afleidings gefokus is, is aangevul deur gesprekke met deelnemers ten einde tot dieper insig te kom rakende bepaalde kennis, insigte en sienswyses, asook die heg van betekenisse deur deelnemers self. Vir die doel van hierdie studie is daar egter slegs op die kwantitatiewe aspek gefokus.

\section{Navorsingsontwerp}

Die navorsingsontwerp kan waarskynlik ten beste beskryf word as nie-eksperimentele oorsignavorsing.

\section{Psigometriese eienskappe van die RMBV (Hall et al. 1986)}

Die RMBV meet toetslinge se relatiewe voorkeur vir 12 beroepskategorieë. Beroepe word gerangskik in nege kolomme wat elk 12 beroepe bevat. Toetslinge word versoek om die 12 beroepe per kolom in voorkeurorde te rangskik (vanaf 1 [sterkste voorkeur] tot 12 [sterkste afkeur]). Die minimum-telling wat 'n persoon in enige kategorie kon behaal, was 9 (sterkste moontlike voorkeur) en die maksimum-telling was 108 (sterkste moontlike afkeur). Die Handleiding vir die vraelys (Hall et al. 1986) dui aan dat die vraelys in Brittanje op 'n steekproef van 351 leerders toegepas is. Bevredigende halfverdelingsbetroubaarhede sowel as toets-hertoetsbetroubaarhede is gevind. Die vraelys (wat op die Raad vir Gesondheidsberoepe van Suid-Afrika se lys van amptelik goedgekeurde toetse verskyn) is in 1976 op 'n steekproef van 211 swart leerders en 209 wit Suid-Afrikaanse toetslinge toegepas en daar is bevind dat toetslinge se resultate grotendeels ooreenstem in die sin dat wit en swart toetslinge ooreenstemmend in terme van die 12 beroepskategorieë gereageer het. 


\section{Prosedure: Statistiese toetse om die toepaslikheid van die aangepaste vraelys te bepaal}

Die volgende statistiese toetse is uitgevoer:

- Om die vraelys se betroubaarheid te bepaal: Berekening van Cronbach $\alpha$ 's.

- Om die statistiese (asook praktiese) betekenisvolheid (effek) van verskille tussen manlike en vroulike deelnemers te bepaal: Die uitvoer van $t$-toetse, asook die berekening van Cohen se d-waardes.

- Om te bepaal of daar verskille bestaan tussen die gemiddelde tellings van die drie verskillende taalgroepe in die 12 beroepskategorieë: Uitvoer van variansie-analise (ANOVA).

- Om te bepaal waar presies die verskille tussen die groepe soos hierbo aangedui, manifesteer (asook die praktiese betekenisvolheid daarvan): Uitvoer van Tukey se HSD-toets.

\section{Toetsing van die vraelys op ' $\mathrm{n}$ groep leerders}

Die vraelys is aanvanklik op'n groep van 30 Graad 11-leerders in 'n plattelandse skool toegepas om moontlike onduidelike items en toetsinstruksies aan die lig te bring. Deelnemers is gevra om aan te dui watter van die beroepe hulle nie verstaan nie. Ooreenkomstig die leerders se terugvoer is enkele van die beroepe vervang deur ander beroepe wat makliker deur leerders verstaan sou word.

\section{Toepassing van die veranderde vraelys vir data-ontleding}

Die aangepaste vraelys is in die tydperk AugustusSeptember 2013 deur die eerste outeur, in samewerking met onderwysers en assistente, by skole afgeneem.

\section{Steekproeftrekking}

In die eerste fase is vier provinsies by wyse van doelsteekproeftrekking geselekteer: een stedelik en drie plattelands of semiplattelands. Vir die doel van hierdie ondersoek is die populasie gedefinieer as alle Graad 11-leerders in openbare hoërskole in Gauteng, Mpumalanga, Limpopo, asook Noordwes. In fase twee is 'n doelsteekproef van agt skole getrek (518 Graad 11-leerders). Skole is volgens onderrigtaal (Afrikaans/Engels) en streek (stedelik/ plattelands/semiplattelands) verdeel. Die frekwensies in terme van a. geslag en b. moedertaalverspreiding word hier onder verskaf (sien Tabelle 1 en 2).

\section{Etiese oorwegings}

Skriftelike toestemming is in 2011 van die uitgewer van die RMBV verkry om die toets in en vir Suid-Afrika aan te pas.

TABEL 1: Frekwensies: Taalgroepe.

\begin{tabular}{lll}
\hline Taalgroep & Frekwensie & \% \\
\hline Afrikaans & 237 & 44.57 \\
Engels & 86 & 55.43 \\
Afrikataal & 192 & - \\
\hline Totaal & $\mathbf{5 1 5}$ & $\mathbf{1 0 0 \dagger}$ \\
\hline
\end{tabular}

$\dagger$, Drie deelnemers het nie hul geslag vermeld nie.
TABEL 2: Frekwensies: Geslagsgroepe.

\begin{tabular}{lccc}
\hline Taal & \multicolumn{2}{c}{ Geslag } & Totaal \\
\cline { 2 - 3 } & Manlik & Vroulik & \\
\hline Afrikaans & 96 & 141 & 237 \\
Engels & 47 & 39 & 86 \\
Afrikataal & 86 & 106 & 192 \\
Totaal & $\mathbf{2 2 9}$ & $\mathbf{2 8 6}$ & $\mathbf{5 1 5}$ \\
\hline
\end{tabular}

TABEL 3: Gemiddeldes en standaardafwykings.

\begin{tabular}{|c|c|c|}
\hline Beroepskategorie & $\bar{x}$ & s \\
\hline Administratiewe aktiwiteite & 66.32 & 14.18 \\
\hline Ingenieurswese en die bou-omgewing & 62.59 & 17.60 \\
\hline Wiskundige en rekeningkundige bedryf & 61.13 & 18.39 \\
\hline Avontuur, die buitelewe, plante en diere & 59.85 & 18.47 \\
\hline Regspraktyk en beskermingsdienste & 59.45 & 15.01 \\
\hline Inligtingstegnologie & 58.93 & 19.53 \\
\hline Woordkuns & 58.69 & 16.65 \\
\hline Verbruikerswetenskap en die gasvryheidsbedryf & 58.46 & 17.36 \\
\hline Maatskaplike, versorgings- en diensgebaseerde beroepe & 57.39 & 15.01 \\
\hline Mediese en paramediese dienste & 57.12 & 18.71 \\
\hline Musiek en die kunste & 56.89 & 16.60 \\
\hline Die toerismebedryf en bemarking & 45.18 & 13.51 \\
\hline
\end{tabular}

Maatreëls is deurgaans getref om die deelnemers se welstand te verseker. Ingeligte instemming is van alle deelnemers, asook alle ouers verkry. Onderwysdepartemente en skoolhoofde betrokke, is insgelyks genader om ingeligte toestemming te verskaf. Alle inligting is as vertroulik gehanteer en terugvoer is aan leerders verskaf. Potensieel onduidelike begrippe is op eerbiedige wyse verduidelik.

\section{Resultate}

\section{Frekwensies}

Die frekwensies in terme van taal en geslag verskyn in Tabelle 1 en 2.

\section{Gemiddeldes en standaardafwykings}

Die gemiddeldes en standaardafwykings vir die volledige steekproef, asook vir die geslagte afsonderlik, verskyn in Tabelle 3 en 4.

\section{Betroubaarheidsbepaling}

DiebetroubaarheidvandieaangepasteveldeismetCronbachse $\alpha$-koëffisiënt, sowel as die halveringsbetroubaarheidsmetode bepaal en verskyn in Tabelle 5 en 6.

Die meeste betroubaarheidskoëffisiënte (Cronbach se $\alpha$-koëffisiënt sowel as die halveringsmetode) is in die orde van 0.70 tot 0.80 .

\section{Vergelykings tussen die geslagsgroepe}

Om die statistiese, maar ook die praktiese betekenisvolheid van verskille tussen geslagte se gemiddelde tellings in die 
TABEL 4: Gemiddeldes en standaardafwykings: Geslagte.

\begin{tabular}{|c|c|c|c|c|}
\hline \multirow[t]{2}{*}{ Beroepskategorie } & \multicolumn{2}{|c|}{ Manlik $\dagger$} & \multicolumn{2}{|c|}{ Vroulik } \\
\hline & $\bar{x}$ & s & $\bar{x}$ & $s$ \\
\hline Woordkuns & 63.60 & 14.95 & 54.65 & 16.89 \\
\hline Administratiewe aktiwiteite & 71.56 & 11.93 & 62.00 & 14.40 \\
\hline Inligtingstegnologie & 50.32 & 18.99 & 65.95 & 17.05 \\
\hline Wiskundige en rekeningkundige bedryf & 56.71 & 18.19 & 64.83 & 17.74 \\
\hline Maatskaplike, versorgings- en diensgebaseerde beroepe & 64.63 & 12.86 & 51.43 & 13.95 \\
\hline Musiek en die kunste & 61.68 & 15.98 & 53.10 & 16.15 \\
\hline Mediese en paramediese dienste & 59.59 & 15.84 & 55.14 & 20.55 \\
\hline Die toerismebedryf en bemarking & 45.43 & 13.17 & 44.89 & 13.77 \\
\hline Verbruikerswetenskap en die gasvryheidsbedryf & 68.14 & 13.59 & 50.56 & 16.08 \\
\hline Ingenieurswese en die bou-omgewing & 50.82 & 14.23 & 72.24 & 13.73 \\
\hline Regspraktyk en beskermingsdienste & 55.71 & 13.62 & 62.42 & 15.46 \\
\hline Avontuur, die buitelewe, plante en diere & 53.81 & 18.61 & 64.79 & 16.88 \\
\hline
\end{tabular}

$\dagger, N=230 ; \$, N=286$

TABEL 5: Cronbach se $\alpha$ 's vir die verskillende velde.

\begin{tabular}{ll}
\hline Veld & Cronbach se $\boldsymbol{\alpha}$ \\
\hline Woordkuns & 0.74 \\
Administratiewe aktiwiteite & 0.69 \\
Inligtingstegnologie & 0.84 \\
Wiskundige en rekeningkundige bedryf & 0.77 \\
Maatskaplike, versorgings- en diensgebaseerde beroepe & 0.63 \\
Musiek en die kunste & 0.70 \\
Mediese en paramediese dienste & 0.78 \\
Die toerismebedryf en bemarking & 0.61 \\
Verbruikerswetenskap en die gasvryheidsbedryf & 0.73 \\
Ingenieurswese en die bou-omgewing & 0.75 \\
Regspraktyk en beskermingsdienste & 0.63 \\
Avontuur, die buitelewe, plante en diere & 0.77 \\
\hline
\end{tabular}

TABEL 6: Halveringsbetroubaarhede vir die verskillende velde.

\begin{tabular}{ll}
\hline Veld & Halveringsbetroubaarheid \\
\hline Woordkuns & 0.80 \\
Administratiewe aktiwiteite & 0.71 \\
Inligtingstegnologie & 0.85 \\
Wiskundige en rekeningkundige bedryf & 0.79 \\
Maatskaplike, versorgings- en diensgebaseerde beroepe & 0.66 \\
Musiek en die kunste & 0.76 \\
Mediese en paramediese dienste & 0.80 \\
Die toerismebedryf en bemarking & 0.70 \\
Verbruikerswetenskap en die gasvryheidsbedryf & 0.77 \\
Ingenieurswese en die bou-omgewing & 0.76 \\
Regspraktyk en beskermingsdienste & 0.69 \\
Avontuur, die buitelewe, plante en diere & 0.82 \\
\hline
\end{tabular}

twaalf beroepskategorieë te bepaal, is $t$-toetse uitgevoer en Cohen se d-waardes bereken. Die resultate verskyn in Tabel 7.

Inspeksie van Tabel 7 toon aan dat die praktiese betekenisvolheid van die verskil tussen die gemiddelde tellings van seuns en dogters (dogters se gemiddelde telling was hoër as seuns s'n) ten opsigte van die kategorieë inligtingstegnologie, asook ingenieurswese en die bouomgewing groot was, terwyl die situasie net omgekeerd was (seuns se gemiddelde telling was hoër as dogters s'n) ten opsigte van die kategorieë maatskaplike, versorgings- en diensgebaseerde beroepe, asook verbruikerswetenskap en die gasvryheidsbedryf.

\section{Bepaling van die statistiese betekenisvolheid van verskille tussen taalgroepe.}

Die statistiese betekenisvolheid van die verskille tussen subgroepe is aan die hand van eenrigting- ANOVA bepaal. Waar F-waardes betekenisvol was op die 5\%-peil, is Tukey se HSD-toets gebruik ten einde te bepaal watter subgroepe statisties betekenisvol van mekaar verskil, gevolg deur Cohen se d-waardes wat die praktiese betekenisvolheid van die verskille aandui.

Eenrigting-ANOVA is tussen groepe uitgevoer om die invloed van moedertaal op RMBV-kategorieë te bepaal. Hoewel Tukey se HSD-toets statisties betekenisvolle verskille aan die lig gebring het ten opsigte van agt van die RMBV-kategorieë (naamlik administratiewe aktiwiteite; die toerismebedryf en bemarking; inligtingstegnologie; ingenieurswese en die bouomgewing; maatskaplike, versorgings- en diensgebaseerde beroepe; regspraktyk en beskermingsdienste; musiek en die kunste; asook vir avontuur, die buitelewe, plante en diere), was die praktiese betekenisvolheid van verskille feitlik deurgaans klein. Slegs in die geval van laasgenoemde (ABPD) was die verskil medium prakties betekenisvol. Tukey se HSD het aangetoon (ANOVA $F=30.75 ; p=0.00$ ) dat die Afrikaanse groep se gemiddelde telling $(\mathrm{M}=53.94, \mathrm{~s}=19.76)$ betekenisvol verskil het van die 'Afrikataalsprekende' groep $(\mathrm{M}=67.39 ; \mathrm{s}=13.48)$ (Cohen se $\mathrm{d}=0.78$; medium effek) en dat die Engelse groep $(\mathrm{M}=59.29$; $\mathrm{s}=18.49)$ se telling ook betekenisvol verskil het van die 'Afrikataalsprekende' groep $(\mathrm{M}=67.39 ; \mathrm{s}=13.48)$ (Cohen se $\mathrm{d}=0.53$; medium effek).

\section{Bespreking}

Die RMBV word reeds vir dekades met groot vrug deur sielkundiges tydens voorligting gebruik. Aangesien toetslinge verplig word om telkens 12 beroepe (in nege groepe) in voorkeurorde te rangskik, fasiliteer dit telkens vir elke toetsling 'n idiosinkratiese, gedifferensieerde oorkoepelende beroepsbelangstellingsprofiel. Die uitslae stel veral beroepsvoorligters in staat om toetslinge te help om 'n gedifferensieerde beeld van hul belangstellings te bekom. In samehang met ander belangvraelyste verskaf die RMBV gebalanseerde belangstellingsprofiele van kliënte. Om hierdie 
TABEL 7: $t$-Toetsresultate vir die bepaling van die betekenisvolheid van verskille tussen geslagte se gemiddelde tellings in die twaalf beroepskategorieë.

\begin{tabular}{|c|c|c|c|c|c|c|c|c|c|}
\hline \multirow[t]{2}{*}{ Beroepskategorie } & \multicolumn{2}{|c|}{$\bar{x}$} & \multirow[t]{2}{*}{$t$-waarde } & \multirow[t]{2}{*}{ gv } & \multirow[t]{2}{*}{$p$} & \multicolumn{2}{|c|}{$s$} & \multirow[t]{2}{*}{ Cohen se d } & \multirow{2}{*}{$\begin{array}{l}\text { Praktiese } \\
\text { betekenisvolheid }\end{array}$} \\
\hline & Manlik & Vroulik & & & & Manlik & Vroulik & & \\
\hline Woordkuns & 63.60 & 54.65 & $6.29 \ddagger$ & 514 & 0.00 & 14.95 & 16.89 & 0.56 & Medium \\
\hline Administratiewe aktiwiteite & 71.56 & 62.00 & $8.08 \dagger$ & 514 & 0.00 & 11.93 & 14.40 & 0.72 & Medium \\
\hline Inligtingstegnologie & 50.32 & 65.95 & $-9.84 \ddagger$ & 514 & 0.00 & 18.99 & 17.05 & 0.87 & Groot \\
\hline Maatskaplike en rekeningkundige bedryf & 56.71 & 64.83 & $-5.11 \ddagger$ & 514 & 0.00 & 18.19 & 17.74 & 0.45 & Klein \\
\hline $\begin{array}{l}\text { Maatskaplike, versorgings- en } \\
\text { diensgebaseerde beroepe }\end{array}$ & 64.63 & 51.43 & $11.05 \ddagger$ & 514 & 0.00 & 12.86 & 13.95 & 0.98 & Groot \\
\hline Musiek en die kunste & 61.68 & 53.10 & $6.03 \ddagger$ & 514 & 0.00 & 15.98 & 16.15 & 0.53 & Medium \\
\hline Mediese en paramediese dienste & 59.59 & 55.14 & $2.70 \dagger$ & 514 & 0.01 & 15.84 & 20.55 & 0.24 & Klein \\
\hline Die toerismebedryf en bemarking & 45.43 & 44.89 & 0.45 & 514 & 0.65 & 13.17 & 13.77 & 0.04 & Klein \\
\hline $\begin{array}{l}\text { Verbruikerswetenskap en die } \\
\text { gasvryheidsbedryf }\end{array}$ & 68.14 & 50.56 & $13.22 \%$ & 514 & 0.00 & 13.59 & 16.08 & 1.17 & Groot \\
\hline Ingenieurswese en die bou-omgewing & 50.82 & 72.24 & $-17.33 \dagger$ & 514 & 0.00 & 14.23 & 13.73 & 1.54 & Groot \\
\hline Regspraktyk en beskermingsdienste & 55.71 & 62.42 & $-5.16 \ddagger$ & 514 & 0.00 & 13.62 & 15.46 & 0.46 & Klein \\
\hline Avontuur, die buitelewe, plante en diere & 53.81 & 64.79 & $-7.02 \ddagger$ & 514 & 0.00 & 18.61 & 16.88 & 0.62 & Medium \\
\hline
\end{tabular}

$\dagger$, Statisties betekenisvol op die 5\%-peil; $\$$, Statisties betekenisvol op die $1 \%$-peil.

rede het die outeurs besluit om die ontwikkelaars te probeer opspoor en hul toestemming te bekom vir die opdatering van die vraelys. Hoewel die huidige steekproef relatief klein is, is die bevindinge voldoende om etlike belangrike afleidings te kan maak.

Die betroubaarheidskoëffisiënte (Cronbach se $\alpha$-koëffisiënt sowel as die halveringsmetode) is oor die algemeen goed of ten minste bevredigend. Daar is egter ruimte vir verbetering; veral ten opsigte van die volgende drie kategorieë: Maatskaplike, versorgings- en diensgebaseerde beroepe; die toerismebedryf en bemarking; asook regspraktyk en beskermingsdienste. Hierdie feit kan waarskynlik onder andere daaraan toegeskryf word dat nie al die beroepe waaruit die betrokke velde bestaan, aan al die leerders bekend is nie (daar is juis ' $n$ poging aangewend om nuwer, meer kontemporêre beroepe in die vraelys in te sluit), of dat sommige leerders bloot nie die terme korrek verstaan het nie. Dit is ook waarskynlik dat sommige leerders ten tye van die toetsing nog nie duidelikheid gehad het oor hul beroepsbelangstellings nie en dus geneig was om inkonsekwente response te verskaf.

Soos verwag is, het seuns 'n hoër mate van belangstelling getoon in die kategorieë inligtingstegnologie, asook ingenieurswese en die bou-omgewing. Dogters het weer meer belang gestel in die kategorieë: maatskaplike versorgings- en diensgebaseerde beroepe, asook verbruikerswetenskap en die gasvryheidsbedryf. Dit dui daarop dat bepaalde beroepskeuse-stereotipes steeds onder die SuidAfrikaanse bevolking floreer. In 'n land soos Suid-Afrika, met 'n groeiende ekonomie en 'n nypende tekort aan veral vrouestudente in ingenieurswese en verwante rigtings, asook inligtingstegnologie-verwante studierigtings, is dit noodsaaklik dat aandag hieraan gegee word (Kraak 2007). Die beoogde ekonomiese groeikoers van $6 \%$ kan onmoontlik behaal word tensy vroue in baie groter getalle vir kwalifikasies in hierdie studierigtings inskryf. Insgelyks bestaan daar 'n nypende en eskalerende tekort aan manlike studente in studierigtings soos die onderwys en verdien hierdie aspek eweneens die aandag van belanghebbendes (Maree in druk).
Daar behoort indringend ondersoek ingestel te word na wyses waarop hierdie aspekte bevredigend gehanteer kan word.

Dit is verder betekenisvol dat medium prakties betekenisvolle verskille slegs in die geval van avontuur, die buitelewe, plante en diere tussen die drie taalgroepe gemanifesteer het. Beide die Afrikaanse en Engelse moedertaalsprekers se gemiddelde tellings het medium betekenisvol verskil van die gemiddelde tellings van die Afrikataalsprekendes. In al twee gevalle was die Afrikataalsprekendes se belangstellingstellings in hierdie kategorie hoër as die tellings van die ander twee taalgroepe (die leser word nogeens daarop gewys dat lae tellings dui op sterker belangstellings en hoër tellings op swakker belangstellings). Die feit dat Afrikataalsprekendes se belangstelling in landbouverwante studierigtings soveel sterker is as dié van hul Afrikaans- en Engelstalige landgenote is geensins verbasend nie: Landbou is verreweg die gesogste 'beroep' onder Afrikataalsprekende Suid-Afrikaners, by uitstek in plattelandse gebiede (Şaul 1995). Die bevinding kan, onder meer, daarop dui dat hulle meer beperkte blootstelling het aan 'ander' beroepsrigtings as hul Afrikaans- en Engelstalige landgenote of dat Afrikataalsprekendes se ouers 'n hoër premie op studie in hierdie rigtings plaas. Laasgenoemde hipotese word versterk deur die algemene onsekerheid wat tans in Afrikaans- en Engelssprekendes se gemoed heers weens welbekende botsende en ontstellende uitsprake oor die landbousektor (wat kortliks daarop neerkom dat witmense se besit van grond toenemend sal moet verminder, dat plase afgeneem sal word van witmense en dat 'wit beheer' oor landbougrond in die toekoms ingrypend sal verminder).

\section{Samevatting}

Samevattend kan verklaar word dat hierdie studie uiters nuttige inligting opgelewer het. Die aangepaste vraelys kan waarskynlik met omsigtigheid gebruik word in die kontekste waarop die steekproef betrekking het. Die vraelys kan egter steeds verfyn word, en verdere navorsing word aangedui ten einde die toepaslikheid daarvan in'n breër konteks te verhoog. 
Ten slotte behoort die volgende wesenlike vrae hier aan die einde gestel te word: Is dit die moeite werd om 'n aansienlike hoeveelheid geld en tyd te belê in die aanpassing van ' $n$ vraelys wat elders in die wêreld ontwikkel is? Of is dit meer aangewese om 'n nuwe, inheemse vraelys te ontwikkel (gebaseer op die grondliggende beginsels vervat in die teoretiese begronding van die RMBV, asook etlike ander vraelyste) en sodanige vraelys te standaardiseer? Die outeurs is van mening dat laasgenoemde opsie dalk aangedui is, eerder as om voort te gaan met die aanpassing en toetsing van die RMBV. Wat ook al die geval: ondanks doemprofete se uitsprake dat die ontwikkeling en/of aanpassing van sielkundige vraelyste eenvoudig tans te tydrowend en koste-oneffektief is, is dit duidelik dat dit wesenlik en ook moontlik is om wel ' $n$ 'positivistiese' belangstellingsvraelys te ontwikkel wat segwaarde in die Suid-Afrikaanse konteks het.

\section{Erkenning \\ Mededingende belange}

Die outeurs verklaar hiermee dat hulle geen finansiële of persoonlike verbintenis het met enige party wat hulle in die skryf van hierdie artikel voordelig of nadelig kon beïnvloed nie.

\section{Outeurbydraes}

J.G.M. (University of Pretoria) het die navorsing gedoen en die artikel geskryf, terwyl J.P. (Nelson Mandela Metropolitan University) die statistiese berekeninge uitgevoer het en die inhoud van die artikel en die statistiese data gekorreleer het.

\section{Literatuurverwysings}

Ainley, J., Jones, W. \& Navaratnam, K.K., 1990, Subject choice in senior secondary school, Australian Publishing Service, Canberra, Australia.

Arthur, M.B., 1994, 'The boundaryless career: A new perspective for organizational inquiry', JournalofOrganizationalBehavior15, 295-306. http://dx.doi.org/10.1002/ job.4030150402

Arthur, M.B. \& Rousseau, D.M., 1996, The boundaryless career: A new employment principle for a new organizational era, Oxford University Press, New York, NY.

Aswathappa, K., 2005, Human resource and personnel management, Tata McGrawHill, Delhi, India.

Baruch, Y., 2004, 'Transforming careers: From linear to multidirectional career paths', Career Development International 9, 58-73. http://dx.doi.org/10.1108/ 13620430410518147

Benko, C. \& Weisberg, A., 2007, Mass career customization, Harvard Business School Press, Boston, MA.

Cochran, L., 1997, Career counselling: A narrative approach, Sage Publications, London, England.

Du Toit, R., 1992, South African vocational interest inventory, HSRC, Pretoria, South Africa.

Gati, I., Fishman-Nadav, Y. \& Shiloh, S., 2006, 'The relations between preferences for using abilities, self-estimated abilities, and measured abilities among career counseling clients', Journal of Vocational Behavior 68, 24-38. http://dx.doi.org/ 10.1016/j.jvb.2005.04.002

Gershuny, J., 1993, 'Post-industrial career structures in Britain', in G. Esping-Andersen (ed.), Changing classes, pp. 136-170, Sage, London, England.

Gevers, J., Du Toit, R. \& Harilall, R., 1995, Manual for the self-directed search questionnaire (South African version), HSRC, Pretoria, South Africa.
Gurri, M., 2013, The revolt of the public and the crisis of authority in the new millennium (Kindle DX version), viewed n.d., from http://www.Amazon.com

Hall, B.A., Halstead, M.E. \& Taylor, T.R., 1986, Test administrator's manual for the Rothwell-Miller Interest Blank, HSRC, Pretoria, South Africa.

Hall, D.T., 1996, 'Protean careers of the 21st century', Academy of Management Executive 10, 8-16. http://dx.doi.org/10.5465/AME.1996.3145315

Handy, C., 1995, The age of unreason, Arrow Books, London, England.

Hartung, P.J., 2013, 'Career construction counseling', in A. Di Fabio \& J.G. Maree (eds.) Psychology of career counselling: New challenges for a new era, pp. 15-28, Nova Psychology of career coun
Science, New York, NY.

Holland, J.L., 1985, Making vocational choices: A theory of vocational personalities and work environments, 2 nd edn., Prentice Hall, Upper Saddle River, NJ.

Holland, J.L., 1997, Making vocational choices: A theory of vocational personalities and work environments, Psychological Assessment Resources, Odessa, FL.

Kraak, A., 2007, Human resources development preview, HSRC, Cape Town, South Africa.

Kraak, A., 2010, 'The collapse of the graduate labour market in South Africa: Evidence from recent studies', Research in Post-Compulsory Education 15, 81-102. http://dx.doi.org/10.1080/13596740903565384

Kuder, G.F., 1975, Kuder general interest survey manual, Science Research Associates, Chicago, IL.

Kuder, G.F., 1977, Activity interests and occupational choice, Science Research Associates, Chicago, IL.

Low, K.S.D., Mijung, Y., Roberts, B.W. \& Rounds, J., 2005, 'Stability of vocational interests from early adolescence to middle adulthood: A quantitative review of longitudinal studies', Psychological Bulletin 131, 713-737. http://dx.doi.org/ 10.1037/0033-2909.131.5.713

Mainiero, L.A. \& Sullivan, S.E., 2005, 'Kaleidoscope careers: an alternative explanation for the opt-out revolution', Academy of Management Executive 19, 106-123. http://dx.doi.org/10.5465/ÁME.2005.15841962

Maree, J. G., 2013a, 'Latest developments in career counselling in South Africa: Towards a positive approach', South African Journal of Psychology 43, 409-421. http://dx.doi.org/10.1177/0081246313504691

Maree, J.G., 2013b, Counselling for career construction: Connecting life themes to construct life portraits, turning pain into hope, Sense, Rotterdam, The Netherlands. construct life portraits, turning pain into hope,
$\mathrm{http}: / / \mathrm{dx}$.doi.org/10.1007/978-94-6209-272-3

Maree, J.G., 2012, " $n$ Voorlopige studie tot die waarde van 'n gekombineerde kwantitatiewe-kwalitatiewe benadering tot beroepsvoorligting met 'n natuurwetenskapstudent: 'n longitudinale gevalstudie', Suid-Afrikaanse Tydskrif natuurwetenskapstudent: ' $\mathrm{n}$ longitudinale gevalstudie, Suid-Afrikaanse
vir Natuurwetenskap en Tegnologie 31, http://dx.doi.org/satnt.v31i1.383

Maree, J.G., in press, 'Barriers to access to and success in higher education: intervention guidelines', South African Journal of Higher Education.

Miller, K.M., 1968, Manual for the Rothwell-Miller interest blank, NFER, Windsor, England.

Miller, K.M., Tyler, B. \& Rothwell, J.W., 1994, Rothwell-Miller interest blank manual, Revised Australian edn, Miller \& Tyler, London, England.

Parsons, F., 1909, Choosing a vocation, Houghton-Mifflin, Boston, MA.

Patrick, L., Care, E. \& Ainley, M., 2011, 'The relationship between vocational interests, self-efficacy, and achievement in the prediction of educational pathways', Journal of Career Assessment 19(1), 61-74. http://dx.doi.org/10.1177/ pathways, Journal of

Savickas, M.L., 1993, 'Career counseling in the postmodern era', Journal of Cognitive Psychotherapy: An International Quarterly 7, 205-215.

Savickas, M.L., 2000, 'Renovating the psychology of careers for the twentyfirst century', in A. Collin \& R.A. Young (eds.), The future of career pp. 53-68, Cambridge University, Cambridge, MA. http://dx.doi.org/10.1017/ CBO9780511520853.004

Savickas, M.L., 2005, 'The theory and practice of career construction', in S. Brown \& R.W. Lent (eds.), Career development and counseling: Putting theory and research to work, pp. 42-70, John Wiley New York, NY.

Savickas, M.L., 2007, 'Reshaping the story of career counselling', in K. Maree (ed.), Shaping the story - a guide to facilitating narrative counselling, pp. 1-3, Van Schaik, Pretoria, South Africa.

Savickas, M.L., 2011a, Career counseling, American Psychological Association, Washington, DC.

Savickas, M.L., 2011b, 'new questions for vocational psychology: Premises, paradigms, and practices', Journal of Career Assessment 19, 251-258. http://dx.doi.org/ $10.1177 / 1069072710395532$

Savickas, M.L., 2013, Ten ideas that changed career development, pp. 1-3, NCDA Broken Arrow, OK.

Saul, M., 1995, 'Economic life in African villages and towns', in P.M. Martin \& P. O'Meara (eds.), Africa, 3rd edn., pp. 190-210, Indiana University Press, Bloomington. 